\title{
Localization of vepsians hystorical toponyms in contemporary mapping
}

\author{
A. A. Bashkarev ${ }^{1}$
}

${ }^{1}$ Peter the Great St.Petersburg Polytechnic University, 29 Politechnicheskaya str., St. Petersburg, 195251, Russian Federation

DOI: $10.18255 / 1996-5648-2021-3-350-359$

Research article Full text in Russian

The article is analyzed the aspects of the historical mapping of Vepsians toponyms in the Leningrad and Vologda regions of Russia. The purpose of creating the map was to apply all the existing and most of the previously existing Vepsians toponyms to the topographical basis. In addition to the localization of toponyms, the map was prepared by localizing the names of some hydronyms and hills in the Vepsians language. The map was created during several ethnographic expeditions and communication with local residents in 2010-2019, as well as the analysis of previously collected toponymic material. The implementation of the project to create a map is outlined in the text. The main problems of localization of Vepsians toponyms are described and approaches to their solution are proposed. The main sources of information for the toponyms mapping are listed. The author assesses the prospects of distribution and use of toponymic maps in scientific research.

Keywords: vepsians, settlements, toponymy, hydronymy, oikonymy, localization, cartography, mapping

\section{INFORMATION ABOUT AUTHORS}

\author{
Bashkarev, Andrey A. E-mail: bashkarev@mail.ru \\ Cand. Sc. (Politics), Associate Professor
}




\title{
Локализация исторических вепсских топонимов на современной картографической основе
}

\author{
A. А. Башкарев ${ }^{1}$
}

${ }^{1}$ Санкт-Петербургский политехнический университет Петра Великого, ул. Политехническая, 29, Санкт-Петербург, 195251, Российская Федерация

DOI: $10.18255 / 1996-5648-2021-3-350-359$

УДК 908+528.9: 910.27

Научная статья

В данной статье рассмотрены аспекты фрормирования исторической карты вепсских топонимов Ленинградской и Вологодской областей России. Целью создания карты являлось нанесение на топографическую основу всех существующих и большинства ранее существовавших в указанных регионах вепсских топонимов. Кроме локализации топонимов, при подготовке карты была выполнена локализация названий части гидронимов и объектов рельефа на вепсском языке. Создание карты реализовывалось в ходе проведения нескольких полевых экспедиций и работы с информантами в 2010-2019 гг., а также анализа ранее собранного топонимического материала. Изложена поэтапная реализация проекта по созданию карты, рассмотрены основные проблемы локализации топонимов, а также подходы к их решению. Проанализированы основные источники информации для карты вепсских топонимов. Дана оценка перспективам распространения и использования топонимических карт в научных исследованиях.

Ключевые слова: вепсы; поселения; топонимика; гидронимия; ойконимия; локализация; картография; картирование

\section{ИНФОРМАЦИЯ ОБ АВТОРАХ}

Башкарев, Андрей Альбертович

E-mail: bashkarev@mail.ru

Кандидат политических наук, доцент

Исследование процессов формирования топонимов, их трансорормации в историческом контексте и современного использования является одной из важнейших задач для сохранения историко-культурного наследия малых народов. Исследования в области истории и лингвистики 
оказываются неизбежно связанными с эволюцией топонимии, в частности с особенностями формирования ойконимов и гидронимов и воздействием различных фракторов на эти процессы. Так, сохранение и влияние субстратов в контексте изменение ареала расселения этнических групп прослеживается в том числе через сопоставление картографического материала за различные периоды. Этнолингвистический потенциал топонимии базируется на целом ряде объективно присущих ей особенностей. Массовость топонимического материала позволяет оперировать большими количествами названий, что выгодно характеризует топонимию на фроне фррагментарных и в большинстве своем поздних письменных источников или этнически плохо интерпретируемых и к тому же обычно неполных, отрывочных археологических свидетельств. Исключительную ценность представляет привязка топонимов и топонимных типов к определенному времени и определенной территории [1]. В свою очередь создание карт позволяет визуализировать этноязыковые процессы для их интерпретации в историческом контексте, прослеживать сокращение или расширение ареалов расселения.

Изучение вепсской топонимии в последние десятилетия осуществлялось достаточно интенсивно. Наибольшее внимание языковым процессам в этой сорере уделяет И. И. Муллонен. В исследованиях данного автора детально анализируется исторический контекст фрормирования топонимии и гидронимии территории традиционного проживания вепсов [2-3]. Изучению данных процессов в области топонимии уделяли внимание и другие исследователи [4, с. 6-22; 5, с. 117-119]. Исследования были продолжены и в более поздний период, становясь основой фундаментальных работ. В частности, в 2018 г. коллективами авторов были подготовлены «Лингвистический атлас вепсского языка»" ${ }^{1}$ и «Этноконфессиональный атлас Ленинградской области» ${ }^{2}$. С учетом фрормата данных изданий в них был включен соответствующий картографический материал, однако комплексное отражение вепсских топонимов на единой карте оставалось актуальным.

Основой для проведения и публикации упомянутых работ неизбежно являлся сбор материалов в ходе полевых исследований. Такая работа, в частности, осуществлялась сотрудниками ИЯЛИ КарНЦРАН в 1970-1980-х гг., когда уровень старения вепсского этноса было не столь значительным и работа с информантами могла осуществляться в до-

${ }^{1}$ Лингвистический атлас вепсского языка (ЛАВЯ) / под общ. ред. Н. Г. Зайцевой. СПб.: Нестор-История, 2019. 572 с.

${ }^{2}$ Этноконфессиональный иллюстрированный атлас Ленинградской области / О. М. Фишман, М. Л. Засецкая, Г. А. Исаченко [и др.]. СПб.: Инкери, 2017. 656 с. 
статочной мере. Учитывая наблюдавшиеся в середине XX в. процессы вынужденной миграции вепсов с территорий исконного проживания [6, с. 153-167; 7, с 95-106; 8, с. 55-63], участники исследований проводили запись свидетельств информантов в местах переселения. Помимо сбора сведений о материально-бытовой сфере и духовной культуре, осуществлялась также запись топонимических названий и их интерпретация информантами. Это позволило сорормировать картотеку топонимов ИЯЛИ, что в последующие годы позволило обобщить и структурировать данные с использованием современных геоинформационных технологий [9, с. 245-246]. В более поздние десятилетия сбор информации по вепсской топонимии был продолжен отдельными краеведами и этнографами [10-11].

В условиях старения и естественной убыли вепсского населения, а также его вынужденной миграции с исконных мест проживания в ХХ в. сбор информации о микротопонимах к началу 2000-х г. усложнился. С учетом характерной для формирования вепсских деревень «гнездовой» системы расселения [3, с. 70; 12, с. 48-49], с помощью картотеки и дополнительных полевых исследований оказались возможными поиск и сохранение инорормации о вепсских названиях собственно «гнезд», объединяющих, в свою очередь, группы микротопонимов. В то же время сами микротопонимы, формировавшие «гнезда», в условиях резкого сокращения численности жителей вепсских поселений выходили из обихода; сбор информации о них и в особенности их локализация оказались значительно затруднены. Кроме того, при фрормировании во второй половине XX в. картотеки микротопонимов по объективным причинам не осуществлялась фиксация их географических координат, что в отсутствие инорормантов также негативно повлияло на процесс последующей локализации.

Автор данной публикации в 2007 г. поставил пред собой задачу создания карты вепсских топонимов Ленинградской и части Вологодской областей. Исконная вепсская территория в республике Карелия (бывш. Вепсская национальная волость с центром в п. Шелтозеро) в проект умышленно не включалась в силу отсутствия подходящей топографической основы. Однако составление предполагалось в будущем, после отработки методов создания карты на примере Ленинградской и Вологодской областей (рис. 1). Планировалось впервые нанести на крупномасштабную (1:100 000) карту весь корпус известных вепсских топонимов и микротопонимов (в т. ч. ойконимов) в ее границах отображения, наряду с гидронимами.

Комплексная локализация вепсских топонимов непосредственно на картографической основе до этого момента не производилась. Несмотря на фрундаментальные исследования, реализованные ИЯЛИ КарНЦ РАН, сохранялась задача визуализации расположения топонимов через созда- 
ние карты для значительной части вепсского ареала. Имевшиеся карты представляли собой лишь схематичное изображение отдельных вепсских поселений, выполняя прикладные задачи визуального сопровождения конкретных научных статей; в иных случаях ареал отображался целиком, но не в крупномасштабном представлении и без детализации. В то же время уже имелся опыт частичной локализации карельских ${ }^{3}$ и фринских топонимов, реализованный в виде соответствующих карт, который также был учтен. $\mathcal{K}$ сожалению, масштаб данных карт (1:240 000 и 1:220 000, в 1 см - 2,4 км и 2,2 км соответственно) не позволил локализовать названия микротопонимов на фринском и карельском языках.

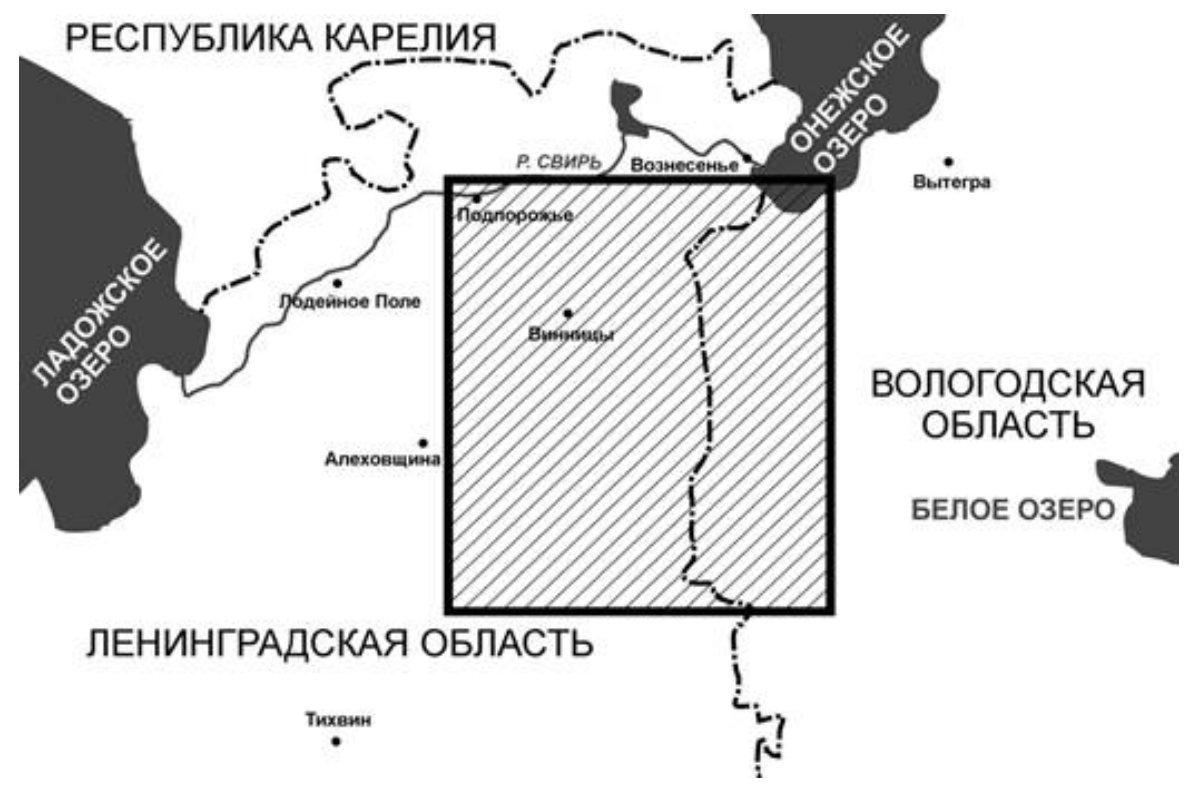

Рисунок 1. Схема расположения границ создаваемой карты, включая территорию средневепсского и частично южновепсского ареала

При составлении карты вепсских топонимов, с учетом отмеченных выше сложностей со сбором материалов, использовался комплексный подход к их поиску, обобщению, сопоставлению и в конечном счете локализации: работа с картотекой ИЯЛИ КарНЦ РАН, анализ архивных топографических карт, обобщение сведений из научных публикаций, а также проведение автором собственных полевых исследований - в первую очередь для выявления микротопонимов и их записи на вепсском языке.

${ }^{3}$ Юго-Западная Карелия. Северное Приладожье. Venäjän Lounais-Karjala. Laatokan Karjala. Автодорожная и туристическая карта. СПб.: Дискус Медиа, 2004.

${ }^{4}$ Pietari, Karjalan kannas: Санкт-Петербург, Карельский перешеек. СПб.: Карта Лтд, 2005. 
При этом как картотека, так и свидетельства информантов содержали вепсские названия не только официально существующих или существовавших в XX в. топонимов, но и неофициальных, обиходных названий природных объектов или частей поселений. При условии отсутствия официальных названий на русском или вепсском языках, но наличии сведений о них в картотеке или свидетельствах информантов такие названия наносились на карту, хотя их число не было значительным.

Важно отметить, что в советский период наблюдалось расхождение в официальных и обиходных, являвшихся исконными названиях гнезд вепсских поселений, характерное, прежде всего, для Подпорожского района Ленинградской области (офиц. Мининская при названии гнезда Ладва, вепс. Ladv, офиц. Миницкая при названии гнезда Мягозеро, вепс.

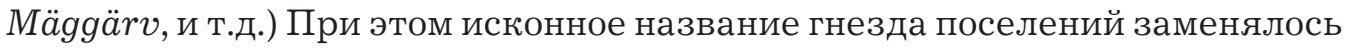
названием его части, являвшейся в советский период административным центром поселения. Данное положение, сохраняющееся и в настоящее время, усложняет процесс локализации топонимов, однако нивелируется повсеместным доминирующим использованием исконных названий вместо официальных, в том числе в транспортной и дорожной системах.

Создаваемая историческая карта должна была отвечать определенному набору критериев:

а) отражать местность исторического расселения средних (оятских) и южных вепсов, т. е. восток Ленинградской и запад Вологодской областей (в т. ч. бывший Винницкий район Ленинградской области с преимущественно вепсским населением, административно существовавший в 1927-1963 гг.);

б) обладать масштабом не менее 1:120 000, т. е. в 1 см. - 1,2 км. для возможности нанесения названий малых населенных пунктов, частей деревень, хуторов, упраздненных и нежилых деревень, а также гидронимов, в т. ч. малых рек, ручьев, болот и т. д.;

в) отражать трансформацию административно-территориального деления местности с 1927 г. по настоящее время (прежние и современные границы районов);

г) отражать реальную, наиболее объективную картину состояния объектов на местности, в особенности границ населенных пунктов и дорожной сети на данный момент для возможности соотнесения пользователем карты исторической информации с современным инфраструктурным состоянием. Также подобное сопоставление позволило бы наглядно продемонстрировать сокращение вепсских поселений - от частей гнезд до их полного упразднения. 
Работа над созданием карты началась в 2007 г. Для получения современной топографической основы в 2012 г. к сотрудничеству было приглашено картографическое издательство «ЗАО Карта ЛТД», предоставившее картографическую базу данных для формирования исторического слоя карты. Использование картографической базы данных было осуществлено по лицензионному соглашению автора с издательством ${ }^{5}$, предполагающему некоммерческое использование материала в научно-исследовательской работе и его публикацию в научных статьях. В 2012-2017 гг. реализовывалось формирование исторического слоя информации для последующего размещения на топографической основе. В частности, для отражения топонимов на вепсском языке в 2013 г. был реализован анализ картотеки ИЯЛИ КарНЦ РАН, с 2005 г. автором также проводились регулярные полевые исследования в Бокситогорском, Тихвинским и Подпорожском районах Ленинградской области, а также в Вытегорском районе Вологодской области с целью сбора информации о топонимах. При этом анализировались сведения, полученные от переселенных информантов, ранее проживавших в уже несуществующих поселениях (рис. 2). С 2017 г. начата работа по локализации на карте гидронимов и названий объектов рельефа (прежде всего, возвышенностей). Реализация работы над формированием карты освещалась автором в ходе докладов на научных конференциях в Санкт-Петербурге (РЭМ) и Петрозаводске (ИЯЛИ КарНЦ РАН).

На данный момент карта полностью отражает практически все вепсские топонимы, существующие или существовавшие в XX в. на русском языке и в массе своей - на вепсском. Работа по наполнению карты основными топонимами (названиями крупных деревень) на вепсском языке завершена. Тем не менее на основе публикуемых результатов новых исследований ведется дополнение микротопонимами на вепсском языке - в основном это названия частей деревень с учетом «гнездовой» системы расселения. Масштаб основной карты 1: 100000 (в 1 см - 1 км) позволяет отразить микртопонимы, в т. ч. ойконимы (рис. 3). Для отдельных гнезд вепсских поселений с высокой существовавшей или существующей плотностью расположения исторических топонимов (Ладва, вепс. Ladv, Мягозеро, вепс. Mäggärv, Шимозеро, вепс. Šimgär’, Пяжозеро, вепс. Рäžar) peализованы карты в еще более детальном масштабе 1: 50000 (в 1 см - 500 м).

\footnotetext{
${ }^{5}$ Лицензионное соглашение № 299 от 28.09.2012 г.
} 


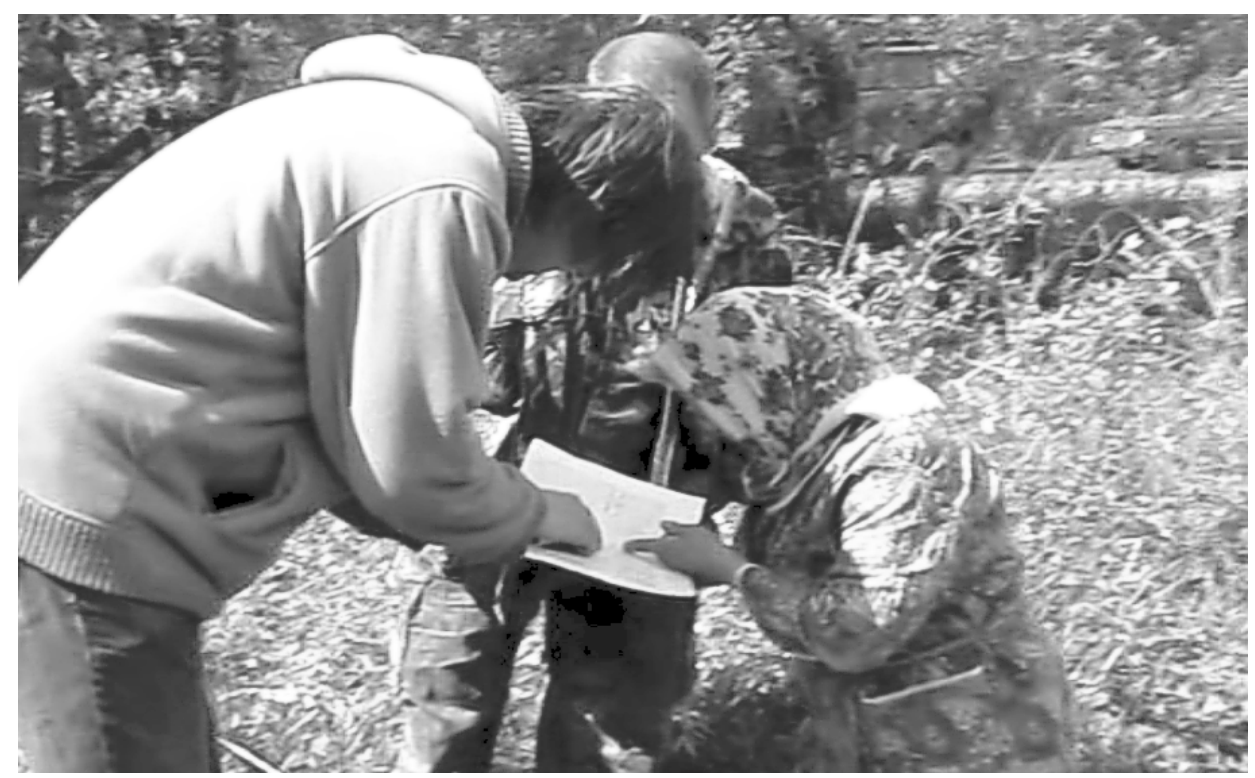

Рисунок 2. Работа с информантом в ходе локализации топонимов на вепсском языке (бывшая жительница упраздненной деревни Каменный Наволок (вепс. Kivinem) указывает на расположение микротопонимов и обозначает их вепсские названия). Июнь 2012 г., ур. Шимозеро (вепс. Šimgär`), Вытегорский район Вологодской области. Фото автора

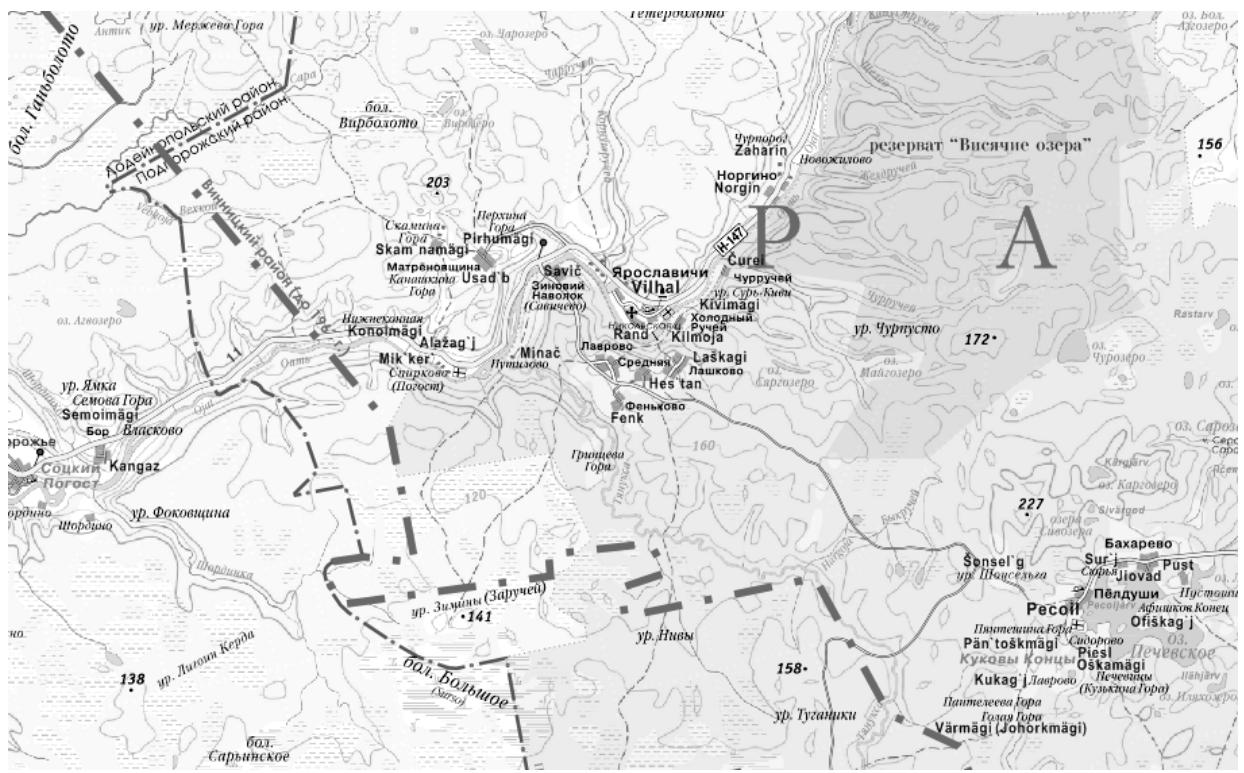

Рисунок 3. Вепсские топонимы и схема существующего и прежнего административно-территориального деления на карте. Фрагмент с поселениями Ярославичи (вепс. Vilhal) и Пелдуши (вепс. Ресоil). Ленинградская область 
Башкарев А. А.

Составленная карта вепсских топонимов на данный момент доступна для служебного пользования в научно-исследовательских целях. Полезной могла бы стать и ее фрагментарная публикация для иллюстративного сопровождения научных статей автора. Возможности дальнейшего финансирования могут позволить заключить новое лицензионное соглашение с картографическим издательством, предоставившим основу для наложения слоя исторической информации, включающей топонимы на вепсском языке. В этом случае реальностью могла бы стать публикация карты в полном объеме и с обеспечением широкого доступа к ней всех заинтересованных исследователей.

Кроме того, продолжение работы несомненно привело бы к обеспечению возможностей дальнейшей локализации вепсских топонимов в местностях, на данный момент не входящих в границы карты - это прежде всего Прионежский район республики Карелия (северные вепсы), а также часть Бокситогорского района Ленинградской области (южные вепсы). Такая деятельность может базироваться на уже отработанной методике, сочетающей исследования картотек, научных монографий, краеведческих полевых исследований. Активизация представителей вепсских этнолокальных групп в социальных сетях также технически расширяет границы сбора информации о топонимах, однако их последующая локализация на карте в виде названий на вепсском языке должна предваряться экспертизой научного сообщества.

Существующая на данный момент в фрорматах, адаптированных прежде всего для печати, карта может быть впоследствии трансформирована в электронный геоинформационный источник, что обеспечит поиск и группировку топонимов в соответствии со стоящими научными задачами. Такое направление деятельности представляется перспективным в контексте обеспечения мультиформатного доступа к данным карты и тиражированию содержащихся в ней топонимических сведений.

\section{Ссылки}

1. Муллонен И. И. Проблемы интерпретации этноязыковой истории Европейского севера России на материале топонимики // Вестник истории, литературы, искусства. М.: Наука, 2015. Т. 10. С. 93-107.

2. Муллонен И. И. Гидронимия бассейна реки Ояти, Петрозаводск, 1988. 161 с.

3. Муллонен И. И. Очерки вепсской топонимии. СПб.: Наука, 1994. 156 с.

4. Зайцева Н. Г. Диалекты вепсского языка в контексте этнолингвистической географии // Финно-угорский мир. 2017. № 3 (32). С. 6-22. 
5. Строгальщикова 3. И. Вепсы: региональные особенности этнодемографических процессов (1938-2010 годы) // Läänemeresoome väikekeelte ja kultuuride konverents Pühendatud professor Tiit-Rein Viitso 75. sünnipäevale. 2013. C. 117-119.

6. Башкарев А. А. Миграция вепсского населения Вологодской области в ХХ веке // Россия в глобальном мире. 2014. № 4 (27). С. 153-167.

7. Лапин В. А. Шимозеры - трагедия диалекта [о сохранении вепс. яз. в Волог. обл.] // Вепсы и этнокультурные перемены XX века: материалы семинара (Санкт-Петербург, 5-6 октября 2006 г.). Хельсинки, 2007. С. 95-106.

8. Петухов А. В. Административная разобщенность - фрактор ускорения ассимиляции вепсов // Проблемы истории и культуры вепсской народности. Петрозаводск: Изд-во Карельского филиала АН СССР, 1989. С. 55-63.

9. Захарова Е. В. Геоинформационные технологии в сохранении и исследовании топонимии Карелии // Х конгресс этнографов и антропологов России: тезисы докладов / редкол.: отв. ред. М. Ю. Мартынова, Л. А. Лопуленко, Н. А. Белова. M.: Издательство Института этнологии и антропологии им. Н.Н. Миклухо-Маклая РАН, 2013. С. 245-246.

10. Курилов М. А. Край озер. Деревни Верхнего Приоятья. СПб.: Контраст, 2018. 256 с.: ил.

11. Курилов М. А. Край озер. Часть 2: Деревни Верхнего Приоятья. СПб.: Контраст, 2019. 206 с.: ил.

12. Егоров С. Б. Традиционная культура южных вепсов: дис.... канд. ист. наук. СПб., 2014. 279 с. 